\title{
THE HEMODYNAMICS OF THYROTOXICOSIS IN MAN WITH SPECIAL REFERENCE TO CORONARY BLOOD FLOW AND MYOCARDIAL OXYGEN METABOLISM ${ }^{1}$
}

\author{
By GEORGE G. ROWE, JOHN H. HUSTON,2 ARVIN B. WEINSTEIN, HERMAN \\ TUCHMAN, ${ }^{8}$ JOHN F. BROWN, ${ }^{8}$ AND CHARLES W. CRUMPTON WITH THE \\ TECHNICAL ASSISTANCE OF AUDREY PETERSON, BERYL WELCH, AND \\ PHYLLIS FOSSHAGE
}

(From the Cardio-Pulmonary Research Laboratory and the Department of Medicine, University of Wisconsin Medical School, and the University Hospitals, Madison, Wis.)

(Submitted for publication September 28, 1955 ; accepted November 16, 1955)

For many years the hemodynamics of thyrotoxicosis have been of interest to clinicians. Blood flow through the extremities was assumed to be increased in thyrotoxicosis because of the high rate of heat elimination when the hand was placed in a calorimeter (1). Several workers found an increase in cardiac output in thyrotoxic subjects using the oxygen content of arm vein blood in the Fick formula (2-4). Similar findings were obtained using the nitrous oxide (5) and acetylene methods $(6,7)$. The velocity of circulation, as determined by the rate of transit of radioactive materials through the cardiovascular system is accelerated in thyrotoxicosis and becomes normal after effective treatment $(8,9)$. Circulation time measured by sodium dehydrocholate in patients with thyrotoxicosis is more rapid than normal (10).

Blalock and Harrison using oxygen content of right ventricular blood in the Fick formula showed that in dogs thyroid feeding produced an increase in cardiac output while thyroidectomy produced a decrease in output (11).

Experiments concerning the myocardium directly have shown an increase in $\mathrm{O}_{2}$ uptake/gram of muscle. Direct measurement of $\mathrm{O}_{2}$ consumption in the Warburg apparatus demonstrated an increase in oxygen utilization by the thyroid stimulated myocardium as shown in the isolated beating

1 This investigation was supported in part by grants to the Cardio-Pulmonary Research Laboratory of the University of Wisconsin from the Wisconsin Heart Association, Wisconsin Alumni Research Foundation, and National Heart Institute of the National Institutes of Health, Public Health Service.

2 Wisconsin Heart Association Research Fellow.

${ }^{8}$ Heart Trainee of the National Heart Institute, U. S. Public Health Service, 1955. rabbit auricle (12). Dock and Lewis established that thyroid feeding to rats increased the total body oxygen consumption (13). Then by converting the animals to a heart lung preparation they demonstrated that the increased oxygen consumption by the heart and lungs was directly related to the cardiac rate and the oxygen consumption per beat remained unchanged. They concluded that the increase in cardiac oxygen metabolism was explained by the increased cardiac rate and was not otherwise related to the hypermetabolic state.

In view of this rather consistent body of data the report of normal myocardial oxygen consumption in thyrotoxic patients despite an increase in total metabolism is surprising (14). It appeared that these observations might be re-evaluated in a larger number of patients, studying them before and after treatment for thyrotoxicosis so that each patient could serve as his own control.

\section{MATERIAL AND METHODS}

Hemodynamic studies were made of ten patients believed to have thyrotoxicosis on the basis of clinical and laboratory examination. The plan was to determine the cardiac output and coronary blood flow of each patient in the thyrotoxic state, to treat him with radioactive iodine or surgery, and subsequent to clinical improvement to repeat the hemodynamic studies. All patients were treated with radioactive iodine except No. 6 (L. M.), who had subtotal thyroidectomy.

All studies were done in the fasting, post-absorptive state and every effort was made to obtain basal conditions. Cardiac output was determined by the Fick principle, coronary blood flow by the nitrous oxide saturation method utilizing a blood-myocardial partition coefficient of 1 (15). Pressures were recorded with Statham strain gauges and the direct writing Sanborn poly-viso. The usual formulae were used for calculation of cardiac work and peripheral resistance. 
The final series consists of eight acceptable complete studies. The ninth patient, (F. K.) had the lowest initial $\mathrm{I}^{20}$ uptake in the series, 49 per cent, and although the radioactive iodine uptake decreased following therapy he did not attain a satisfactory clinical response. He failed to gain weight and continued to experience his symptoms of nervousness, tachycardia, palpitation and dyspnea. Additional investigation at this time revealed a severe anxiety tension state associated with a very difficult home situation. This patient's data are shown at the bottom of the table but are excluded from the averages because it is felt that his primary disease was not thyrotoxicosis. However, statistical calculations were made with these data included and excluded (Table I) without producing significant differences in the over-all pattern. The tenth patient was a 22-year-old woman with moderately severe thyrotoxicosis and mild hypertension who returned to the hospital in the euthyroid state subsequent to treatment. However, because she was pregnant and had developed more severe hypertension, it was felt that data collected from her would serve no purpose for this series so re-study was not done. In patient G. A. a satisfactory initial determination of coronary blood flow was impossible from the first nitrous oxide curves but since he was still thyrotoxic at the time of his return to the hospital hemodynamic studies were repeated before and after he had responded to further treatment. Results in this case will be cited later. Comparisons were also made between hyperthyroid, treated hyperthyroid and nine normal subjects studied in our laboratory.

\section{RESULTS}

Results of the study are summarized in Table I. It is apparent that these patients responded to treatment of thyrotoxicosis in the usual fashion with a gain of weight, decrease in heart rate and oxygen consumption per square meter body surface and a lessening of radioactive iodine uptake by the thyroid. Although no significant change occurred in the systemic mean arterial blood pressure, there was a fall in the pulmonary arterial blood pressure $(p<0.01)$. This differing response in the two circulations resulted in a significant increase in total peripheral resistance $(p<0.05)$ with no change in the pulmonary resistance. There was a 50 per cent decrease in right ventricular work index $(p<0.01)$ but, although the left ventricular work index decreased 28 per cent, this was not significant $(p<0.1)$. However, the major change in cardiac output in patient G. A. occurred after his initial, but only partially successful, treatment. Although this study was incomplete, the cardiac output data are satisfactory. If the second study be replaced by this determination, statistical analysis reveals a significant decrease in left ventricular work index for the entire group ( $p<0.05)$. The decrease in rate ( -28 per cent) was so similar to the fall in cardiac index ( 37 per cent) that no significant change in stroke index occurred.

Observations on the myocardial metabolism revealed that successful treatment was followed by significant changes in the coronary vascular resistance $(+70$ per cent $p<0.01)$, coronary blood flow ( -38 per cent $p<0.01$ ), cardiac metabolic rate for oxygen per 100 grams of myocardial tissue $(-37$ per cent $p<0.01)$ and the cardiac metabolic rate for oxygen per beat $(-17$ per cent $\mathrm{p}<0.05)$. When the patients with thyrotoxicosis were compared to normal subjects, see Table I, there were significant increases in heart rate $(p<$ 0.01 ), oxygen consumption ( $p<0.02)$, mean pulmonary arterial pressure $(p<0.05)$, cardiac in$\operatorname{dex}(\mathrm{p}<0.05)$, left and right ventricular work index $(p<0.02)$, coronary blood flow $(p<$ $0.05)$, and cardiac oxygen utilization $(p<0.05)$ in the former. Our data concerning the normal coronary blood flow and myocardial oxygen extraction and utilization compare favorably with Bing's 18 normal subjects (14). Conversely, following treatment, comparison of post-thyrotoxic patients with normals revealed no significant differences in the hemodynamic and metabolic state.

\section{DISCUSSION}

This study indicates that contrary to previously published observations (14) the myocardium participates in the increase in oxygen consumption characteristic of all body tissues in thyrotoxicosis. This hypermetabolism is accompanied by an increase in coronary blood flow, a decrease in coronary vascular resistance, and an increase in oxygen consumption per beat. It seems clear since there is an increase in oxygen consumption per beat that the cardiac oxygen utilization is related not only to the increase in cardiac rate but to the general hypermetabolism of the myocardium as well. If the left ventricular work or left ventricular work index be divided by the myocardial oxygen consumption per 100 grams of tissue, an index of efficiency is obtained. Although these indices did not change, comparison of figures obtained by this method would be subject to errors inherent in 
ROWE, HUSTON, WEINSTEIN, TUCHMAN, BROWN, AND CRUMPTON

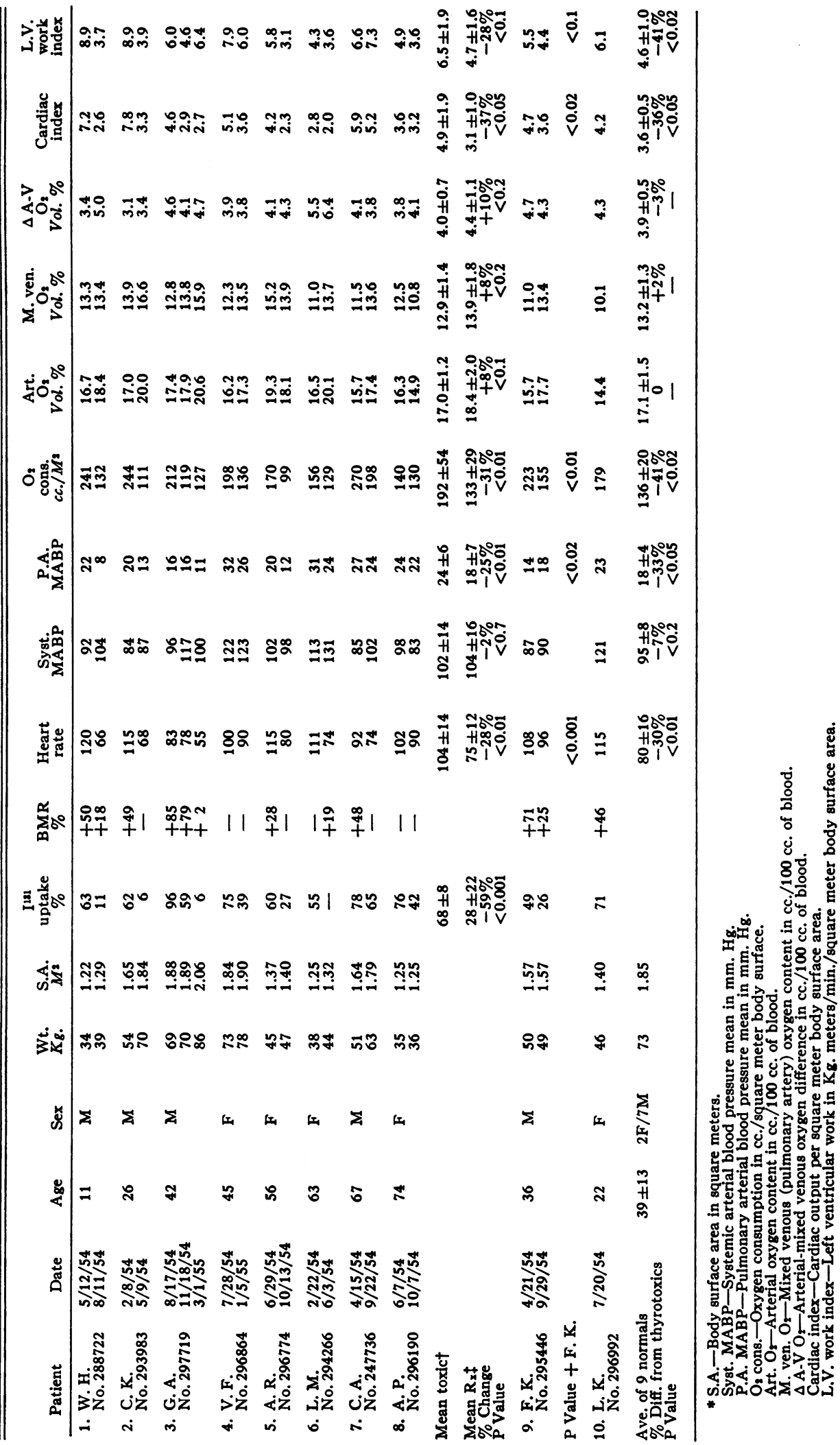




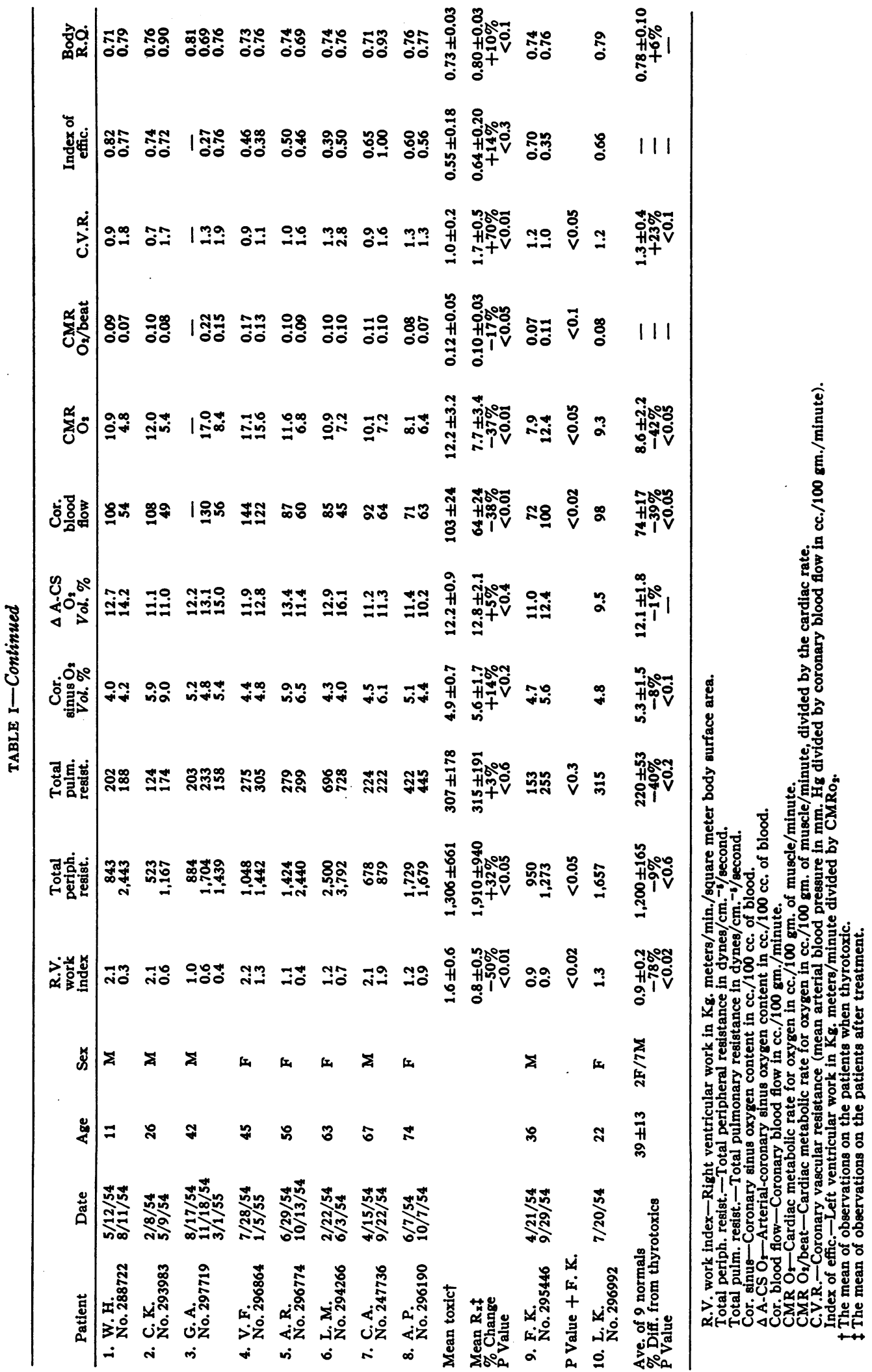


estimation of left ventricular weight should any change in myocardial weight have occurred during the interim between studies (average 3.9 months). Without such specific and presently unobtainable information, no speculation concerning relative efficiency of normal and thyrotoxic heart muscle is justified. Although there was a slight increase in body respiratory quotient in the second as compared to the first study, this change was not statistically significant. This trend may be related to the fact that these patients were studied at the end of a 15-hour fasting period, and owing to their hypermetabolism, had more nearly exhausted their glycogen stores than at the time of the second study.

When both treated and untreated thyrotoxic patients are grouped, significant direct correlations emerge between $\mathrm{I}^{131}$ uptake and the cardiac index $(p<0.05)$, left ventricular work index ( $p<$ $0.01)$, and coronary blood flow $(p<0.02)$. The relation between $\mathrm{I}^{131}$ uptake and myocardial oxygen uptake was not significant $(p<0.1)$. Since the oxygen consumption per square meter is the numerator of the cardiac index equation, it is not valid to calculate the correlation between $B M R$ and cardiac index; the arteriovenous oxygen difference remained constant and obviously a direct relation has to exist. A significant correlation between cardiac output and coronary blood flow existed $(p<0.05)$ with the fraction of cardiac output which perfused each 100 grams of left ventricular muscle remaining 2.1 per cent in both treated and untreated patients.

\section{SUMMARY AND CONCLUSIONS}

1. Hemodynamic observations in patients with thyrotoxicosis are reported. In eight patients studies were made before and after treatment. The results were compared with those from nine normal subjects.

2. Evidence is presented that the hypermetabolic state of thyrotoxicosis includes the myocardium since there is a significant increase in coronary blood flow and cardiac metabolic rate for oxygen.

3. Following specific treatment, the cardiac output, cardiac work, coronary blood flow and myocardial oxygen consumption returned to normal, and the coronary vascular resistance increased.

\section{REFERENCES}

1. Stewart, G. N., Studies on the circulation in man. The blood flow in the hands and feet in normal and pathological cases. Harvey Lect.; 1912-13, 8, 86.

2. Davies, H. W., Meakins, J., and Sands, J., The influence of circulatory disturbances on the gaseous exchange of the blood. V. The blood gases and circulation rate in hyperthyroidism. Heart, 1924, 11, 299.

3. Rabinowitch, I. M., and Bazin, E. V., The output of the heart per beat in hyperthyroidism. Arch. Int. Med., 1926, 38, 566.

4. Burwell, C. S., Smith, W. C., and Neighbors, DeW., The output of the heart in thyrotoxicosis, with the report of a case of thyrotoxicosis combined with primary pernicious anemia. Am. J. M. Sc., 1929, 178, 157.

5. Fullerton, C. W., and Harrop, G. A., Jr., The cardiac output in hyperthyroidism. Bull. Johns Hopkins Hosp., 1930, 46, 203.

6. Liljestrand, G., and Stenström, N., Clinical studies on the work of the heart during rest: I. Blood flow and blood pressure in exophthalmic goiter. Acta. med. Scandinav., 1925, 63, 99.

7. Boothby, W. M., and Rynearson, E. H., Increase in circulation rate produced by exophthalmic goiter. Arch. Int. Med., 1935, 55, 547.

8. Blumgart, H. L., The velocity of blood flow in health and disease. The velocity of blood flow in man and its relation to other measurements of the circulation. Medicine, 1931, 10, 1.

9. Blumgart, H. L., Gargill, S. L., and Gilligan, D. R., Studies on the velocity of blood flow. XIII. The circulatory response to thyrotoxicosis. J. Clin. Invest., 1931, 9, 69.

10. Tarr, L., Oppenheimer, B. S., and Sager, R. V., The circulation time in various clinical conditions determined by the use of sodium dehydrocholate. Am. Heart J., 1933, 8, 766.

11. Blalock, A., and Harrison, T. R., The effects of thyroidectomy and thyroid feeding on the cardiac output. Study number four on the regulation of circulation. Surg., Gynec. \& Obst., 1927, 44, 617.

12. Andrus, E. C., and McEachern, D., The cardiac manifestations of hyperthyroidism. Am. J. M. Sc., 1932, 183, 741.

13. Dock, W., and Lewis, J. K., The effect of thyroid feeding on the oxygen consumption of the heart and of other tissues. J. Physiol., 1932, 74, 401.

14. Bing, R. J., The coronary circulation in health and disease as studied by coronary sinus catheterization. Bull. New York Acad. Med., 1951, 27, 407.

15. Eckenhoff, J. E., Hafkenschiel, J. H., Harmel, M. H., Goodale, W. T., Lubin, M., Bing, R. J., and Kety, S. S., Measurement of coronary blood flow by the nitrous oxide method. Am. J. Physiol., 1948, 152, 356. 